\title{
APRESENTAÇÃO
}

\section{UM ESPAÇO PARA PALAVRAS, MEMÓRIAS E SABERES: CONTRIBUTOS DE UMA (RE)VISTA AO LONGE}

DOI: http://dx.doi.org/10.1590/2236-3459/67396

\author{
Maria Stephanou \\ Universidade Federal do Rio Grande do Sul, Brasil.
}

\section{$\cos 80$}

Silêncio das pedras

é o início

das palavras?

(Manoel de Barros, 2014)

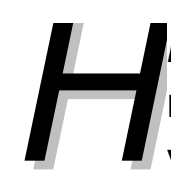

istória da Educação vem a público em seu número 50. Em meia centena de números concedeu espaço para palavras, tornou possível socializar saberes, por vezes dissonantes, outras convergentes, alguns anunciaram tendências, outros vislumbramentos de irrupções novas. Constitui-se espaço do diverso. Temas constantes ou inusitados, abordagens renovadas, umas revisitadas. 50 números perfazem quase 20 anos. Estamos às vésperas desse momento, logo ali estará abril de 2017, quando completaremos duas décadas de publicação ininterrupta. Cumprimos diversos caminhos e assumimos desafios, sugeridos pelos associados da Associação Sul-Rio-Grandense de Pesquisadores em História da Educação - Asphe -, solicitados pelos pares, prescritos pelas políticas de avaliação. Diferentes editores, distintas instituições de acolhida, autores frequentes ou de uma só passagem, especificidades nacionais ou estrangeiras, estiveram e estão aqui em cena, assim como as temporalidades variadas, seja quanto aos momentos, acontecimentos ou durações, que têm sido abordadas, antes e neste número. Enfim, 50 números constituem registro de memória de uma parte apenas, não menos substantiva, do campo de estudos da História da Educação, memória que é provisão para o futuro, vista ao longe. 
História da Educação, nestes cerca de 20 anos, pode ser lida e relida no atravessamento dos acontecimentos sucedidos de 1997 a 2016, sob diferentes grandezas e intensidades. Terão os historiadores da educação transpirado pelos poros das palavras, tecidas como narrativas do passado - sempre presente? -, os discursos, as impressões, os afetamentos experimentados a cada tempo, daqueles acontecimentos singulares ou especiais? Ou melhor, se os acontecimentos são, como nos ensina Certeau (1994), o que eles se tornam, seremos capazes de examinar tradições e mudanças nas abordagens da história da educação, suas narrativas, perfilações teóricas, eleição de objetos, atravessados pelos acontecimentos do tempo presente, de modo a pensarmos em como se constituem tão somente em seu depois (Dosse, 2013)?

Em meio às interrupções e aberturas provocadas pelos eventos que tiveram ou têm lugar na vida brasileira e internacional no tempo transcorrido desde a publicação do número 49, maio a agosto de 2016, quando enfeixamos aqui, número 50, uma entrevista, um dossiê, diversos artigos, duas resenhas e um documento, quais são os silêncios das pedras? Puderam converter-se em palavras? Ou ainda aguardam o que se tornarão? Parece cada vez mais imperioso retomar as palavras de Georges Duby (1998) quando afirma que "o historiador tem o dever de não se fechar no passado e de refletir assiduamente sobre os problemas de seu tempo" (p. 9). Não restam dúvidas de que os problemas de nosso tempo se nos apresentam em sua opacidade. Tão mais presentes, mais nebulosos, indecifráveis. Ainda não somos inteiramente capazes de compreender seus efeitos, pois estão em pleno processo de tornar-se. Apesar disso mobilizam nossos pensamentos e sentimentos. Não saímos ilesos de atentados, terremotos, processos de impeachment, guerras e bombardeios, missões de salvamento da imigração em massa, em pleno mar, que nos acometem. Ainda precisaremos de tempo para nos aproximarmos da complexidade desses acontecimentos. Ainda assim vale a ressalva de François Dosse (2013):

A constatação do caráter ao mesmo tempo enigmático e indefinido do acontecimento infere outra leitura histórica e novas tarefas ao historiador profissional. A primeira entre elas é preservar a própria abertura do acontecimento, sua capacidade em suscitar a liberdade daqueles que pensam e agem na sua esteira exercendo ao mesmo tempo seu senso crítico. (p. 340)

Cremos que não se esgotou o entendimento, e portanto vale frisá-lo, de que o historiador, e aquele da Educação igualmente, mesmo que não se aperceba, ou, pragmaticamente, se esquive do emaranhado do presente, seja por sua opacidade, seja por seu caráter enigmático, está a revelar, está a testemunhar, pelos seus escritos, de suas narrativas públicas, o seu tempo, os seus movimentos de recriação do passado, suas escolhas, silenciamentos, enfim, seus sonhos, intuições, devaneios. Se ao seu trabalho puder acrescer o senso crítico para manter-se à margem da repetição, para ousar duvidar ou implodir algumas verdades, então o campo de sua inserção poderá tornar-se aquele da abertura do acontecimento. $E$ da liberdade constantemente em perigo e a preservar, referida por Dosse (2013) no excerto acima.

Quais as ressonâncias ou, inversamente, as provocações que os artigos reunidos neste número 50 fomentaram para a escrita dessas iniciais digressões? Mais do que o conteúdo particular de cada artigo, algo de seu conjunto, de sua contemporaneidade, 
desde à submissão até à vitalidade e diversidade do campo que eles indiciam, o conjunto levou-nos a indagar as ressonâncias do tempo vivido em suas escritas, análises, escolhas, enfim, nos eventos historiográficos que produzem. Afinal, como ensina Paul Veyne, "um historiador não dá a palavra aos romanos: ele fala por eles" (apud Le Roux, 2011, p. 368). Eis porque, incontáveis vezes, a solidão da página branca acomete os historiadores, sabedores que são da responsabilidade de escutar os mortos com os olhos (Chartier, 2010) e do quanto suas obras, hoje ou num futuro próximo, estão/estarão sujeitas a contestações, desdobramentos, aperfeiçoamentos, pois o saber historiográfico, encharcado do presente, reinventa-se a cada dia (Sales, 2011).

Registramos aqui, em agosto de 2016, quando vimos a público apresentar o número 50 de História da Educação, nossa condição de historiadores imersos entre os grandes tumultos da democracia (Rancière, 2014), acontecimento em vias de tornar-se.

\section{História da Educação número 50: arranjos e composição}

Inspirada pelas repercussões na comunidade de pesquisadores da educação, sobretudo do Brasil, das entrevistas aqui publicadas de Pierre Caspard, historiador francês de importantes obras e contributos à história da educação, n. 42 de 2014, e aquela de Roberto Sani, historiador italiano, n. 49 de 2016, neste número Maria Helena Camara Bastos, coeditora, brinda os leitores com o testemunho, em nova entrevista, de Agustín Escolano Benito, reconhecido historiador da educação espanhol. O intuito maior, além do registro e provisão aos jovens pesquisadores, é de intensificar o conhecimento e multiplicar as leituras de sua produção, aqui já reconhecida com a publicação, entre outros, n. 47 de 2015, de seu discurso quando da solenidade de outorga do titulo de Doutor Honoris Causa pela Universidade de Lisboa. Para Bastos o processo de internacionalização das universidades e das pesquisas, sobretudo na pós-graduação, estão a exigir um conhecimento maior de autores referencia em contexto internacional, que atuam em espaços de pesquisa como o Centro Internacional de la Cultura Escolar Ceince - localizado na Espanha.

O professor Escolano discorre, inicialmente, sobre seu encontro com a História da Educação, nutrido, em boa medida, pelas inquietações e inconformidades frente ao presente da educação formal e em busca de uma historia que viesse a formular algumas chaves à compreensão da cultura escolar vigente. Em sua entrevista ressalta a importância de seus processos de formação como professor e como pesquisador, o lugar central das práticas de leitura, alguns de seus professores inspiradores e os itinerários descontínuos de suas investigações, cujas temáticas, abordagens e objetivos foram diversos, embora um fio de Ariadne tenha tecido uma trama imbricada entre eles. Destaca-se, e impõe-se sublinhar, a narrativa acerca da criação e institucionalização do Centro Internacional de la Cultura Escolar - Ceince - um espaço decisivo à preservação do patrimônio etnohistórico da escola na Espanha, mas não restritamente a ela, referindo, então, pesquisadores de diversos países que compareceram ou estão articulados ao Centro, dentre os quais aponta as relações com pesquisadores brasileiros. 
Por fim, o autor discorre sobre perspectivas da História da Educação na Espanha, o desenvolvimento do que denomina sua projeção investigadora e, resistindo a um momento de novo pragmatismo tecnicista no ensino superior, considera que a história da educação vem sobrevivendo e se afirmando não só na esfera acadêmica, mas também na sociedade mais ampla.

Efetivamente, embora sem uma intencionalidade planejada, a entrevista de Escolano figura numa combinação fecunda com o dossiê que consta imediatamente na sequencia do número. Basta demorar-se, na entrevista, na apreciação das capas das obras publicadas pelo autor, no titulo do Centro que coordena, ou nos projetos de pesquisa que coordenou para logo constara que em boa medida convergem no exame de manuais escolares e cultura escolar.

O dossiê Contextos de recepção e interpretação dos manuais escolares, organizado por Gladys Mary Ghizoni Teive, da Universidade do Estado de Santa Catarina, Brasil, em conjunto com Gabriela Ossenbach-Sauter, Universidad Nacional de Educación a Distancia, Espanha, que interseccionam cultura escolar, manuais escolares e contextos de recepção e interpretação, ou seja, dos usos dos manuais. Para as autoras o desafio posto consiste em percorrer caminhos teóricos e metodológicos renovados à pesquisa acerca da manualística escolar, cuja centralidade resida nos receptores das mensagens, professores ou alunos, e nos usos diferenciais das mensagens contidas nos textos escolares.

O dossiê está composto por cinco artigos que, segundo as organizadoras, apresentam investigações realizadas por pesquisadores do Manes, Centro de Investigación en Manuales Escolares, da Espanha, e por pesquisadores brasileiros ligados a este Centro. Os artigos apresentam discussões analíticas e metodológicas para a análise dos contextos de transmissão e recepção, além de uma documentação variada no que tange ao artefato manual escolar, livro texto, livro didático - diversidade de conteúdos; variações espaço-temporais, institucionais - não só quanto à filiação, mas a circulação fora da escola - de níveis de ensino e quanto àqueles que os utilizam alunado, professorado, inspeção - mas também uma ampliação documental, por vezes necessária à compreensão dos processos de recepção dos manuais, como aquela que os indicia em comunicados e atas de reuniões pedagógicas. O texto de apresentação do dossiê apresenta detalhadamente cada um dos artigos que o integram e é mister referir a diversidade institucional dos autores brasileiros que apresentam suas investigações associadas ao Manes.

Os autores dos treze artigos e das duas resenhas aqui publicadas têm filiações institucionais e nacionalidades diversas e atestam, em boa medida, o prestígio e a vitalidade da revista. O número 50 conta com artigos de pesquisadores da Suíça, Espanha, Itália, Portugal, Chile e Brasil. Os estudos se circunscrevem, sobretudo, às diferentes décadas do século 20 , mas registre-se a presença de investigações que examinam o século 19. Eis uma questão de recorrentes indagações: disponibilidade documental? Atenção às urgências do tempo presente? Temáticas de intersecção com a sociologia ou com a política da educação? 
Ao leitor convém ressaltar que alguns artigos da submissão individual guardam afinidade temática, talvez inclusive conceitual ou metodológica, com o dossiê Contextos de recepção e interpretação dos manuais escolares. Assim, a revista oferta outras possibilidades de leitura em torno ao tema dos impressos de educação, as leituras e as apropriações a que estiveram sujeitos. São eles os artigos: Un ejemplo de renovación pedagógica en Canarias durante los años 30: tras el rastro y los retos de las técnicas Freinet, de Manuel Ferraz-Lorenzo, Espanha; $A$ missão educativa da geração intemediária em tempo de guerra: textos para a escola e para a juventude de Luigi Bertelli entre 1914 e 1918, de Anna Ascenzi e Elisabetta Patrizi, Itália; As disputas editoriais no campo do Programa do Livro Didático para o Ensino Fundamental do Instituto Nacional do Livro - Plidef/INL (1971-1976), de Monica Maciel Vahl, Nova Zelândia e Eliane Peres, Brasil; Interdição de leitura e prescrição de textos para a infância e juventude montesclarense (1920-1950), de Geisa Magela Veloso e Gisele Cunha Oliveira, Brasil; Cartilhas e livros didáticos nas escolas pomeranas luteranas no sul Rio Grande do Sul (1900-1940), de Patrícia Weiduschadt e Elomar Tambara, Brasil.

Outros artigos, embora não façam uso do conceito de transnacional, podem ser lidos em sua perspectiva, pois demonstram a circulação internacional de idéias pedagógicas, a transferência ou recriação a partir de experiências do exterior. Em relação ao século 19 Damiano Matasci aborda perspectivas para uma história internacional da educação naquele século a partir do exame da escola republicana na França e sua relação com o estrangeiro, seus modelos e exemplos, havendo menção às exposições universais. Para a ampliação das reflexões a partir deste artigo, sugerimos revisitar um artigo, em particular, publicado no n. 41 de 2013, de autoria de Klaus Dittrich, intitulado As exposições mundiais como meios para a circulação transnacional de conhecimentos sobre o ensino primário durante a segunda metade do século 19.

Outros dois artigos podem ser examinados na chave de leitura proposta - circulação transnacional - e se encontram neste número 50. O primeiro se detém na década de 1930 no Brasil e intitula-se Da Lab School de Chicago às escolas experimentais do Rio de Janeiro dos anos 1930, de Libânia Nacif Xavier e José Geldison Rocha Pinheiro, Brasil. O segundo, intitulado A fábrica Móveis Cimo e seus mobiliários: a escola como um mercado atraente, de Gustavo Rugoni de Sousa e Vera Lucia Gaspar da Silva, Brasil, aborda as relações entre cultura material escolar, mobiliário, entendido como artefato, e mercado escolar voltado às escolas públicas primárias. Temática importante por sua intersecção para a historiografia da educação, os autores intentam contribuir com reflexões acerca da constituição histórica da escola, examinando elementos da cultura material escolar no que concerne, também, às relações entre indústria e Estado, donde o aparelhamento escolar se apresentou na virada do século 19 para o 20, como oportunidade à expansão da indústria, fomentada por recursos públicos e pela necessidade de atendimento ao preceito legal que instituiu a obrigatoriedade escolar. Está no horizonte das reflexões expostas pelo artigo de Rugoni e Gaspar uma discussão acerca da circulação de ideias pedagógicas em escala internacional.

Acrescentamos, ainda, no que concerne à circulação de idéias e modelos pedagógicos em perspectiva transnacional, dois artigos: um deles, de autoria de Norberto Dallabrida e Fabiana Teixeira da Rosa, Brasil, intitulado Circulação de ideias sobre a renovação do ensino secundário na revista Escola Secundária (1957-1961). Entre outros 
aspectos, e no que tange à circulação internacional, demonstram a presença da apreciação/inspiração das classes nouvelles da França e a orientação educacional norteamericana em periódico publicado no Brasil relacionado ao ensino secundário. O outro, de autoria do pesquisador português Carlos Miguel Manique, intitula-se A primeira república portuguesa recria o Ministério da Instrução Pública: um esforço de aproximação aos sistemas escolares europeus, que analisa em que medida, em Portugal, a existência de um Ministério próprio, fundado em uma estrutura administrativa fortemente centralizada para a gestão da escola, contribuiu, a partir de 1913, para a reinstituição definitiva do Ministério da Instrução Pública, e até sensivelmente ao final da Primeira República portuguesa (1926), para a aproximação do sistema português aos sistemas escolares europeus.

Três artigos deste número abordam temáticas específicas e igualmente significativas para o campo de estudos da história da educação. Em A constituição da esfera especializada das ciências da educação na democracia portuguesa, a pesquisadora portuguesa Teresa Teixeira Lopo examina a constituição, em Portugal, do que designa como esfera especializada das Ciências da Educação, entre 1976 e 1987, para o que acompanha a evolução histórica de ciência da educação para ciências, no plural, da educação, associada ao processo de institucionalização universitária e a relação entre oportunidades discursivas, visibilidade do campo disciplinar e atores relevantes.

Maria Stephanou e Mariana Venafre Pereira Souza, em Abecedários em circulação: entre dicionários, impressos e cartilhas escolares, apresentam resultados de pesquisa sobre abecedários, tomados como artefatos culturais, não apenas associados à história da escolarização, mas como invenções seculares na história da cultura escrita. Demonstram que não podem ser circunscritos à escola ou à história da alfabetização porque circularam em diferentes contextos e em diversas práticas de difusão da escrita, de produção artística, registro de genealogias, entre outros. Dentre um conjunto de documentos e estudos historiográficos apresentados, destacam um inventário documental de cartilhas nas quais figuram abecedários, identificadas no Acervo Memória da Cartilha da Universidade Federal do Rio Grande do Sul.

Por fim, em História de uma instituição educacional para o deficiente visual: o Instituto de Cegos do Brasil Central de Uberaba (Minas Gerais, Brasil, 1942-1959), Wandelcy Leão Júnior e Giseli Cristina do Vale Gatti intentam compreender o processo de criação do Instituto na cidade de Uberaba, bem como o papel socioeducativo e a importância que teve na inserção de deficientes visuais na escola regular entre 1942 e 1959.

O número 50 conta, ainda, com duas resenhas elaboradas por autores estrangeiros, um da Espanha, que apresenta obra que aborda a formação de professores numa perspectiva histórica e internacional, e outro do Chile, este último sobre obra de antropólogo chileno que examina um século de desenvolvimento educativo na llha de Páscoa. Para o autor da resenha a obra oferece dados históricos e estatísticos importantes e, sobretudo, questões que possibilitam compreender historicamente a relação que, a partir do continente, foi sustentada em Rapa Nui, Ilha de Páscoa, no âmbito educativo. 
Na seção Acervos e documentos reproduzimos documento que apresenta o plano de ensino, elaborado por José Feliciano de Oliveira, positivista ortodoxo, publicado no jornal Diário Popular, no ano de 1891. Neste defende a não obrigatoriedade do ensino no nível, o que gerou polêmica nos jornais paulistas da época, além de reações do professorado público. Tal documento, segundo Lydiane C. de Oliveira, Brasil, expressa as visões de mundo e de educação no contexto da República recém-proclamada no Brasil.

Em tempos presentes, caracterizados pelos torrenciais e incisivos questionamentos à produção acadêmica brasileira, especialmente em decorrência de metas e modelos prevalecentes de avaliação, História da Educação oferece à leitura não apenas uma diversidade de temas e autores, de abordagens originais ou de aprofundamento, mas, sobretudo, lança ao exercício do debate, da memória, este conjunto de artigos que integram seu exemplar número 50. Quiçá possa produzir novas pautas de trabalho futuro e, pela curiosidade e fruição do saber, venha a sustentar uma vigorosa e renovada produção investigativa no campo da produção historiográfica em educação para uma (re)vista ao longe.

\section{Referências}

BARROS, Manoel de. Escritos em verbal de ave. São Paulo: Leya, 2011.

CERTEAU, Michel de; GIARD, Luce. La prise de parole et autres écrits politiques. Paris: Seuil, 1994.

CHARTIER, Roger. Escutar os mortos com os olhos. Estudos Avançados, v. 24, n. 69, 2010, p. 7-30.

DOSSE, François. Renascimento do acontecimento. São Paulo: Unesp, 2013.

DUBY, Georges. Ano 1000, ano 2000: na pista de nossos medos. São Paulo: Unesp, 1998.

LE ROUX, Patrick. Paul Veyne. In: SALES, Véronique (org.). Os historiadores. São Paulo: Unesp, 2011, p. 351-369.

RANCIĖRE, Jacques. Os nomes da história: ensaios de poética do saber. São Paulo: Unesp, 2014.

SALES, Véronique (org.). Os historiadores. São Paulo: Unesp, 2011.

MARIA STEPHANOU é professora titular da Faculdade de Educação da Universidade Federal do Rio Grande do Sul. Pesquisadora do CNPq, atua junto ao Programa de Pós-Graduação em Educação na linha de pesquisa História, memória e Educação. Doutora em Educação pela UFRGS, realizou seu pós-doutoramento junto ao Institut Français d'Éducation, IFÉ, França. Atua como co-editora de História da Educação desde 2011.

Endereço postal completo: Rua Dr. João Palombini, 144 A. 91751-150 - Porto Alegre - RS - Brasil.

E-mail: mastephanou@gmail.com.

Recebido em 10 de agosto de 2016.

Aceito em 22 de agosto de 2016. 